\title{
Imapinação e história: um diálogo com Gaston Bachelard
}

André Fabiano Voigt *1

Resumo: Este artigo pretende associar o conceito de imaginação em Bachelard às reflexões historiográficas recentes, que relacionam as práticas de escrita da história à dimensão imaginativa do trabalho do historiador. Para realizar este intento, torna-se relevante, inicialmente, sistematizar três aspectos de seu pensamento - suas influências, suas críticas e seus novos elementos.

Palavras-chave: Gaston Bachelard. Imaginação. História.

Imaginação e história tornaram-se palavras antônimas. Estabelecer uma possível relação entre ambas parece, ainda hoje, um preciosismo de teorizadores. Entretanto, retomar a dimensão imaginativa da história é um aspecto fundamental para a compreensão da prática historiadora na atualidade. Mesmo após as várias mudanças de reflexão acerca da história ocorridas durante o século XX - com ênfase nos historiadores franceses relacionados à

\footnotetext{
* Professor Adjunto do Instituto de História da Universidade Federal de Uberlândia (UFU), Doutor em História Cultural pela Universidade Federal de Santa Catarina (UFSC).

Endereço eletrônico: voigtandre@hotmail.com

Endereço para correspondência: Universidade Federal de Uberlândia - Instituto de História - Av. João Naves de Ávila, 2121, Sala 1H53 - Campus Santa Mônica 38400-000 Uberlândia-MG
}

Anos 90, Porto Alegre, v. 16, n. 30, p. 143-156, dez. 2009 
revista Annales - as aporias da verdade em história acabam por bloquear, ainda que indiretamente, qualquer aproximação entre os processos de escrita e suas dimensões imaginativas. Continuase a acreditar, de modo geral, que não cabe ao historiador imaginar.

É relevante salientar que há debates historiográficos recentes que procuram restabelecer uma relação possível entre imaginação e história. ${ }^{2}$ Há autores, contudo, que são referências importantes para a emergência do tema da imaginação na atualidade que não são analisados mais detidamente pelos historiadores, tornando invisíveis suas contribuições intelectuais para as mudanças de reflexão historiográfica ocorridas nas últimas décadas.

Diante deste quadro, propor uma análise mais profunda do tema da imaginação na obra do filósofo francês Gaston Bachelard pode ser um caminho importante a ser trilhado, para compreender a relevância de suas discussões sobre a imaginação nas práticas historiadoras da atualidade.

Em primeiro lugar, é importante destacar que Bachelard não é um "precursor". Sabemos dos perigos de, na análise de um autor, cometer o erro de classificar sua obra como "precursora" de uma nova realidade, sem a observância de sua própria historicidade. ${ }^{3}$ Seus estudos estão diretamente relacionados a um debate já realizado na literatura do século XIX - sobretudo aquela ligada ao Romantismo - acerca do papel da imaginação no ser humano (Higonnet, 1981, p. 18-37). Baudelaire, por exemplo, escreve em seu Salão de 1859 a preponderância da imaginação criadora sobre todas as outras faculdades humanas:

Todo o universo visível é apenas um depósito de imagens e de sinais aos quais a imaginação dará um lugar e um valor relativo; é uma espécie de alimento que a imaginação deve digerir e transformar. Todas as faculdades da alma humana devem ser subordinadas à imaginação, que as requisita todas ao mesmo tempo (Baudelaire, 1993, p. 99).

Além de Baudelaire, o trabalho de Bachelard está alicerçado nos trabalhos de poetas e escritores do Romantismo inglês e ale- 
mão, como Jean-Paul Richter, Novalis, Mary Shelley, entre outros, que são citados na maioria de seus livros acerca da imaginação (Higonnet, 1981, p. 23-25). De um modo geral, a reivindicação de um papel central para a imaginação é uma crítica construída a partir do século XIX ao cientificismo e ao positivismo, que pretendem tornar a realidade um dado objetivo, totalmente previsível e mensurável. Portanto, a obra de Bachelard que trata da imaginação possui uma relação direta com o debate entre o Romantismo e o Positivismo.

Ademais, há inspirações nos trabalhos de autores contemporâneos de Bachelard, que trazem novos elementos à reivindicação da centralidade da imaginação criadora, a partir das vanguardas artísticas do início do século XX. Um dos principais autores que discute este aspecto em seus trabalhos é André Breton, em seu Manifesto Surrealista.

Breton faz uma apologia à imaginação criadora, em uma nova crítica ao realismo positivista:

Reduzir a imaginação à servidão, fosse mesmo o caso de ganhar o que vulgarmente se chama felicidade, é rejeitar o que haja, no fundo de si, de suprema justiça. Só a imaginação me dá contas do que pode ser, e é bastante para suspender por um instante a interdição terrível: é bastante também para que eu me entregue a ela (...) Não é o medo da loucura que nos vai obrigar a hastear a meio-pau a bandeira da imaginação. (...) Ao contrário, a atitude realista inspirada no positivismo, de São Tomás a Anatole France, parece-me hostil a todo impulso de liberação intelectual e moral. Tenho-lhe horror, por ser feita de mediocridade, ódio e insípida presunção (Breton, 1924).

O teórico do surrealismo reivindica, da mesma forma, um lugar ao inconsciente e ao onírico como instâncias presentes na atividade psíquica humana. Estas críticas de Breton foram incorporadas em alguns trechos da obra de Bachelard, sobretudo em seu texto, intitulado Le Surrationalisme (O Surracionalismo), escrito em 1936, quando afirma que o surracionalismo multiplicará 
as ocasiões de pensar, devolvendo à sensibilidade e à razão, em conjunto, a sua fluidez, ao mesmo tempo em que devolverá à razão sua função de turbulência e agressividade (Bachelard, 1972, p. 7). É neste ponto de inflexão entre a razão e a imaginação, entre a arte e a ciência, que se encontra o pensamento Bachelardiano.

Simultaneamente à incorporação de um conjunto descontínuo de inspirações de autores de épocas anteriores e de contemporâneos, Bachelard estabelece seu pensamento a partir de uma crítica a alguns de seus contemporâneos: Henri Bergson, Sigmund Freud e os teóricos da fenomenologia - principalmente Sartre.

Apesar de ter sido diretamente influenciado pelas ideias bergsonianas, Bachelard retoma a ideia de mudança a partir da ideia de movimento de Bergson e a desenvolve. Se Bergson teria afirmado que o estudo científico do movimento a partir de pontos de referência (cinemática) conduziria a sua geometrização, sem entrar no movimento em si, em seu livro O Are os Sonhos, Bachelard aponta que o bergsonismo se restringiu, por vezes, ao mesmo cinematismo, sem atingir seu dinamismo potencial (Bachelard, 1990, p. 264). Com isso, o autor quis esboçar uma crítica a Bergson, sem deixar de ser influenciado por seu pensamento. François Pire, em estudo acerca da imaginação poética em Bachelard, afirma que este teria feito um "bergsonismo contra Bergson" (Pire, 1967, p. 189-191), pretendendo multiplicar o bergsonismo para enriquecê-lo em sua potência de movimento. Embora Bachelard tenha como principal divergência do bergsonismo a questão da temporalidade (Bachelard, 2007), é importante ressaltar que o autor não deixou de ser bergsoniano em vários aspectos de seu pensamento.

Sua crítica a Freud, por outro lado, já é mais contundente. Freud sustenta que o inconsciente é o conjunto de experiências mentais que não se tornaram conscientes - e que se encontram, portanto em um estado "inconsciente" - mas que, ao mesmo tempo, são derivadas necessariamente de experiências anteriores do indivíduo. ${ }^{4}$ Seguindo a mesma linha de raciocínio, Freud afirma em seu ensaio Escritores criativos e devaneio (1908) que a atividade imaginativa é derivada do ato infantil de brincar, pois, na vida adulta, as pessoas param de brincar e substituem o prazer da brin- 
cadeira pelo prazer em devanear. Assim, a imaginação freudiana é a substituição de uma experiência radicada na infância (Freud, 2006). Bachelard, por sua vez, não coloca a imaginação como um conjunto de resíduos de percepções antigas, ressuscitadas pela memória (Pire, 1967, p. 29). Em O Ar e os Sonhos, novamente, Bachelard contradiz uma tradição filosófica que atribui à imaginação a faculdade de formar imagens, afirmando sua capacidade de deformar as imagens fornecidas pela percepção. Quando não é possível pensar em uma multiplicidade de imagens ausentes a partir de uma imagem presente, não há imaginação, mas sim percepção, memória ou hábito (Bachelard, 1990, p.1). Bachelard diferencia radicalmente, portanto, percepção e imaginação. A imaginação é movimento de imagens, percepção é estabilidade das mesmas. No mesmo livro, o filósofo francês critica a psicanálise a respeito do conhecimento dos símbolos:

A psicanálise manipulou frequentemente o conhecimento dos símbolos como se os símbolos fossem conceitos. Pode-se mesmo dizer que os símbolos psicanalíticos são os conceitos fundamentais da pesquisa psicanalítica. Uma vez interpretado, uma vez encontrado seu significado 'inconsciente', o símbolo passa à categoria de simples instrumento de análise e acredita-se não haver mais necessidade de estudá-lo em seu contexto ou em suas variedades (Bachelard, 1990, p. 19).

Por entender a psicanálise como um reducionismo da multiplicidade e da potência da imaginação na psique humana, Bachelard estabelece uma crítica ao alcance das ferramentas de análise psicanalíticas - especialmente as de Freud - para a compreensão do papel da imaginação na vida humana.

Apesar de ter usado, em parte de sua obra, alguns preceitos da fenomenologia para a análise dos processos imaginativos, Bachelard não realizou uma análise fenomenológica aos moldes mais ortodoxos de Husserl ou de Sartre. Os principais teóricos da fenomenologia afirmam que a imaginação é uma faculdade subsidiária da percepção e da ocularidade, e Bachelard critica tais axio- 
mas. Em uma das melhores interpretações da obra Bachelardiana disponível em língua portuguesa, José Américo Motta Pessanha trata, em seu artigo Bachelard: as asas da imaginação, do "vício de ocularidade" (Pessanha, 1991. p. xiii) característico de uma tradição filosófica que afirma ser a imaginação uma faculdade de formar imagens da realidade, a partir da percepção e da consciência. Pessanha apropria-se da separação Bachelardiana entre imaginação formal (reprodutora) e imaginação material (produtora) para inserir o pensamento do filósofo francês em um debate contra a tradição filosófica que atribui à imaginação uma característica de abstração, de "construção subjetiva sensório-intelectual", centralizada no sentido da visão como principal via de acesso ao conhecimento. Conforme Pessanha, a imaginação material Bachelardiana seria tributária da mão, mais do que da ocularidade (Pessanha, 1991, p. xxiii-xxxi). A imaginação material seria, portanto, entender a produção de imagens como acontecimento objetivo, imanente à realidade, e não exterior a ela. Sartre teria, em seu principal escrito acerca do tema - A Imaginação - partido da mesma perspectiva ocularista da tradição filosófica anterior para explicar a imaginação, ligando-a sempre à consciência, quando afirma: "A imagem é um certo tipo de consciência" (Sartre, 1978, p.113). Bachelard iria mais adiante: a fenomenologia Bachelardiana da imagem não é tão-somente uma fenomenologia da consciência, mas também da "consciência devaneadora", "da alma" (Pire, 1967, p. 184). Nesse sentido, Bachelard propõe uma fenomenologia que vai além dos seus cânones tradicionais, além da consciência, além da ocularidade.

Depois de situar o pensamento Bachelardiano em relação a suas inspirações e suas diferenças, pode-se traçar alguns aspectos principais de suas considerações acerca da imaginação.

Há, no vocabulário conceitual do filósofo francês, a definição de duas imaginações que estão em constante imbricação: $a$ imaginação dinâmica e a imaginação material. A imaginação dinâmica, colocada por Bachelard e seus principais críticos como primordial, procura abranger o movimento como uma das principais funções da imaginação. No livro em que discorre a respeito da imaginação dinâmica, $O$ Ar e os Sonhos, Bachelard afirma que uma 
imagem estável "corta as asas à imaginação" (Bachelard, 1990, p. 2). Em outras palavras, sustenta que a imaginação vai além das imagens que forma, e que está, necessariamente, em movimento. À medida que as imagens vão se estabilizando, elas deixam de pertencer à imaginação e se tornam percepção. A partir da diferença estabelecida entre imaginação e percepção - novamente caracterizada como um aspecto singular da obra Bachelardiana - podese ter elementos para medir a relevância e a centralidade da imaginação dinâmica no pensamento do autor, que chega a escrever que a imaginação é uma "mobilidade espiritual", uma função essencial de livre movimento que caracteriza o psiquismo humano em contato com seu mundo exterior. Da mesma forma, atesta que o hábito e a imagem habitual são bloqueios à imaginação criadora (Bachelard, 1990, p. 12). O hábito, encravado na revivência das imagens passadas, não é igual à imaginação, que projeta o ser para o futuro, que é puro movimento, livre da opressão do passado. Além disso, outra evidência da primazia da imaginação dinâmica em relação à material está na afirmação de que a descrição da forma é mais fácil que a descrição do movimento e, por isso, tem sido eclipsada a relevância deste último. Mas o movimento, para Bachelard, seria mais importante (Bachelard, 1990, p. 2). Até mesmo quando trata da "lei das quatro imaginações materiais", que atribui a uma imaginação criadora os quatro elementos - fogo, água, ar e terra - defende que os elementos nunca são imaginados em sua inércia, mas sim em seu dinamismo essencial (Bachelard, 1990, p. 8). Por isso, há em Bachelard uma imanência entre a matéria e o movimento, sem a qual não há imaginação, que é a "força de unidade da alma humana" (Bachelard, 1990, p. 153). Não obstante esta imanência, a imaginação Bachelardiana é, essencialmente, movimento.

A imaginação material, por outro lado, é igualmente importante na obra de Bachelard, na medida em que as formas e as matérias são elementos-chave para o trabalho da imaginação criadora. François Pire, novamente, afirma que o postulado da materialidade da imagem estabelece uma relação matéria-imaginação em dois aspectos: que a matéria "educa" a imaginação e, 
por sua vez, que esta "educa" uma matéria (Pire, 1967, p. 57). A imagem material não é, para Bachelard, um dado abstrato, idealizado pelo intelecto; é o resultado do trabalho da mão humana sobre a matéria:

\begin{abstract}
Matéria e Mão devem estar unidas para formar o ponto essencial do dualismo energético, dualismo ativo que tem uma tonalidade bem diferente daquela do dualismo clássico do objeto e do sujeito, ambos enfraquecidos pela contemplação, em sua inércia, outro em sua ociosidade (Bachelard, 1991b, p. 21).
\end{abstract}

A interação entre matéria e mão é, portanto, uma das principais críticas Bachelardianas à primazia da visão como sentido que mais nos aproximaria da realidade. A "ocularidade" da filosofia ocidental, como já foi tratada neste artigo, é um aspecto que estabelece uma separação abrupta entre o trabalho manual e o mental, hierarquizando-os. Desta maneira, o trabalho intelectual tem se tornado pretensamente superior ao trabalho manual e braçal. Mas Bachelard aproxima o trabalho manual da "mais nobre das nossas faculdades":

O trabalho é - no próprio fundo das substâncias - uma Gênese. Recria imaginativamente, mediante as imagens materiais que o animam, a própria matéria, que se opõe a seus esforços. O homo faber em seu trabalho da matéria não se contenta com o pensamento geométrico de ajustamento; desfruta a solidez íntima dos materiais básicos; desfruta a maleabilidade de todas as matérias que deve vergar. E toda essa fruição já se encontra nas imagens prévias que encorajam ao trabalho (Bachelard, 1991b, p.26).

A partir destas afirmações do autor, pode-se notar que não há uma dissociação entre imaginação e matéria; ambas transformam e são transformadas em seu movimento de interferência mútua. Em um dos primeiros livros do filósofo sobre a imagi- 
nação da matéria, A Agua e os Sonhos, o autor trata da água como elemento crucial da imaginação material devido à sua fluidez. Bachelard, em alusão à filosofia pré-socrática, menciona o mobilismo heraclitiano como uma filosofia total, porquanto combina matéria e movimento no elemento da água - compreendida pelo autor como a "metamorfose ontológica essencial entre o fogo e a terra” (Bachelard, 2002, p. 7).

As duas maneiras de se conceber a imaginação em Bachelard - dinâmica e material - são, portanto, duas formas complementares de se compreender a amplitude do papel que a imaginação exerce no psiquismo humano, entre a profundidade da matéria e a agressividade do movimento. Ambas as expressões imaginativas não são, conforme o autor, produtos da abstração imaterial e subjetiva, mas sim da imanência do imaginário no real, de uma continuidade entre a matéria e o movimento sintetizados pela imaginação.

Se, para haver imaginação, é preciso haver movimento, a temporalidade é um elemento essencial nos processos imaginativos. Para Bachelard, a temporalidade não é uma experiência contínua. Neste ponto, o autor contraria Bergson e não vê na duração a experiência da continuidade, mas a descontinuidade do instante como elemento fundamental do tempo. O tempo Bachelardiano, inspirado pelos escritos do historiador Gaston Roupnel, é uma descontinuidade. Em seu livro, A Intuição do Instante, Bachelard faz a apologia do instante, como no momento de seu texto em que afirma, com Roupnel, que "a verdadeira realidade do tempo é a do instante; a duração é apenas uma construção, desprovida de realidade absoluta" (Bachelard, 2007, p. 29). Esta afirmação está em contraposição à tese bergsoniana da duração, em que sustenta ser a duração a verdadeira realidade do tempo, relegando o instante à categoria de abstração. Nesse sentido, pode-se notar no pensamento Bachelardiano uma tendência a rejeitar a continuidade uma realidade temporal, na medida em que a duração é compreendida como um artificialismo, um falso movimento criado entre os instantes. Do mesmo modo, as noções de hábito e de progresso, na sua análise do livro Siloë, de Roupnel, são retiradas de seu caráter teleológico e colocadas na esfera da 
repetição. A ideia de progresso, diz Bachelard novamente citando Roupnel, "está logicamente associada à idéia de recomeço e da repetição" (Bachelard, 2007, p. 82). Não há uma continuidade que seja visível senão mediante a repetição. Por sua vez, a repetição não pode ser compreendida aqui como o eterno retorno do mesmo, mas aquilo que sempre se diferencia ao se repetir.

A descontinuidade Bachelardiana está também na sua concepção de memória. Em seu livro A Poética do Espaço, Bachelard afirma a descontinuidade da memória e a função unificadora da imaginação: "Toda memória precisa ser reimaginada. Temos na memória microfilmes que só podem ser lidos quando recebem a luz viva da imaginação" (Bachelard, 2008, p. 181). O tema da descontinuidade, centrada no instante - e não na duração bergsoniana - será um dos aspetos singulares da crítica de Bachelard à noção de temporalidade colocada por outros autores.

Neste momento da análise da imaginação Bachelardiana, tomada em seus três aspectos discutidos até então - a imaginação dinâmica, a imaginação material e a temporalidade centrada no instante - é possível levar estas considerações para pensar pontualmente a história e o ofício do historiador. Contudo, é importante colocar duas ressalvas iniciais: a primeira, que Bachelard não era historiador e não exercia um diálogo direto com historiadores - exceto o trabalho de Roupnel; a segunda, que as mudanças ocorridas durante o século XX nas maneiras de se compreender a história não foram inspiradas diretamente por Bachelard. Em alguns casos, as suas considerações são contemporâneas às mudanças nos modos de pensar a história e o ofício do historiador, relacionadas quase sempre às primeiras décadas da revista Annales. Entretanto, isto não impede que se possam fazer aproximações interessantes entre o pensamento Bachelardiano e as transformações ocorridas no fazer historiográfico.

Primeiramente, a relação entre a imaginação dinâmica e material oferece-nos a possibilidade de pensar a história como movimento e matéria. Até o início do século XX, a história era o lugar do progresso, da evolução da humanidade em estádios necessários para chegar ao ápice do momento presente. Mas o progresso é a continuidade construída a partir de instantes descontínuos, a pro- 
jeção cinemática de instantes estáticos rumo à consecução de um fim metafísico, sem a observância do movimento próprio de cada instante. $\mathrm{O}$ abandono gradual da noção teleológica de progresso na história acompanha a ideia da descontinuidade temporal, da relação entre os acontecimentos como peças de um quebra-cabeça que não se encaixam, da artificialidade das construções de falsos movimentos a partir dos fatos tomados de maneira estática. O progresso passa a existir como eterno recomeço, como "continuidade da coragem na descontinuidade das tentativas" (Bachelard, 2007, p. 80). Ao mesmo tempo, a história volta-se para a matéria. Antes, estava ligada à vida dos grandes feitos e dos grandes personagens, ao cumprimento dos grandes desígnios humanos. Aos poucos, o sentido da história foi se aproximando das coletividades anônimas, de seus costumes, de sua vida material, da toponímia do lugar em que viviam. Enfim, houve a aproximação do sentido da história daquilo que Jacques Rancière chamou de "geografização do sentido", de uma matéria em que a vida está encravada e dela faz parte, fora dos movimentos criados pelos grandes eventos. ${ }^{5}$ Há, então, o desligamento gradual de uma metafísica do progresso para a aceitação de um ritmo criado pela própria descontinuidade da vida, aproximando a história de uma obra de arte, que atua diretamente na matéria e a transforma, numa escrita que cria espaços, ao invés de simplesmente descrevê-los ingenuamente "como eles realmente aconteceram". O historiador que imagina é um autor que, paradoxalmente, perde a sua ingenuidade ao escrever as ações humanas ao longo do tempo. Vê que não pode haver uma temporalidade construída sem um espaço, uma matéria que lhe é imanente, mas que é recriada a cada vez que é trabalhada pelas suas mãos.

Além disso, a imaginação é aquilo que faz com que os instantes descontínuos possam ser lidos em nossa memória e até mesmo na memória deixada pelos vestígios. Marc Bloch, quando escreve que o historiador, em sua tarefa de conhecer por meio de vestígios, pode ser comparado àquele que desenrola a bobina de um filme no sentido inverso das sequências, em que apenas a última película está intacta (Bloch, 2001, p. 67), deixa em suspenso a afirmação de que só uma atitude imaginativa do historiador pode 
recuperar as películas restantes daquele filme, pois jamais saberemos exatamente o que estava ali. Por outro lado, quando desenrolamos a bobina a partir a última película, damos um novo significado ao passado, sem descartar o que foi encontrado, ao mesmo tempo em que o recriamos.

Por último, ao aproximarmos a imaginação Bachelardiana das formas de se conceber a história na atualidade, é possível notar uma convergência em querer "do ponto de vista da própria vida, buscar compreender o passado pelo presente, longe de um empenho incessante de explicar o presente pelo passado"(Bachelard, 2007 , p. 24-25), pois, afinal, "nunca somos verdadeiros historiadores; somos sempre um pouco poetas" (Bachelard, 2008, p. 26).

\section{Imagination and History: a dialogue with Gaston Bachelard}

Abstract: This article intends to associate Bachelard's concept of imagination to the recent historiographical reflections that make connections among the practices of writing history and the imaginative dimension of the historian's work. To carry out this intention, it is relevant, initially, to systematize three aspects of his thought - his influences, his criticism and his new elements.

Keywords: Gaston Bachelard. Imagination. History.

\section{Notas}

${ }^{1}$ Ver, acerca deste assunto, os livros de: Ricoeur, 1994-1997; Ricoeur, 2007; Lima, 2006; Dosse, 2003; White, 1995; White, 1994; Albuquerque Júnior, 2007.

${ }^{2}$ Embora esta crítica tenha sido realizada no campo da história das ciências, as observações de Georges Canguilhem podem ser úteis para que tenhamos o mesmo cuidado na análise de noções e conceitos a partir de pretensos "precursores" (Canguilhem, 1994, p. 9-23).

${ }^{3}$ Este pensamento permeia toda a obra de Freud, embora esteja mais explícito em dois de seus trabalhos: $A$ interpretação dos sonhos e O inconsciente (Freud, 2006).

${ }^{4}$ Este debate acerca da revolução histórica do século XX, ocorrida sobretudo a partir dos articulistas da revista Annales, é longamente tratado por Jacques Rancière em dois de seus livros: Os Nomes da História e Políticas da Escrita (Rancière, 1994, 1995). 


\section{André Fabiano Voigt}

\section{Referências:}

ALBUQUERQUE JÚNIOR, Durval Muniz. História. A arte de inventar o passado. Bauru, SP: EDUSC, 2007.

BACHELARD, Gaston. A Água e os Sonhos. São Paulo: Martins Fontes, 2002. - A Intuição do Instante. Campinas: Verus, 2007. - A Poética do Espaço. São Paulo: Martins Fontes, 2008. - A Terra e os Devaneios da Vontade. São Paulo: Martins Fontes, 1991b.

BACHELARD, Gaston. Le surrationalisme. In: . L'Engagement Rationaliste. Paris: PUF, 1972. . O Ar e os Sonhos. São Paulo: Martins Fontes, 1990.

BAUDELAIRE, Charles. Salão de 1859. In: - Obras estéticas: filosofia e imaginação criadora. Petrópolis: Vozes, 1993.

BLOCH, Marc. Apologia da História, ou o ofício do historiador. Rio de Janeiro: Jorge Zahar, 2001.

BRETON, André. Manifesto do Surrealismo (1924). Disponível em: <http:// www.culturabrasil.pro.br/ zip/breton.pdf>. Acesso em: 4 jan. 2009.

CANGUILHEM,Georges. L'objet de l'histoire des sciences. In: . Études d'histoire et de philosophie des sciences. Paris: Vrin, 1994. p. 9-23.

DOSSE, François. A História. Bauru, SP: EDUSC, 2003.

FREUD, Sigmund. Obras Completas. Rio de Janeiro: Imago, 2006. Vols. IV e XIV. HIGONNET, Margaret R. Bachelard and the Romantic Imagination. Comparative Literature, Durham (EUA), Vol. 33, No 1 (Winter 1981), p. 18-37. Disponível em: <http://www.jstor.org/stable/1770415 >. Acesso em: 08 abr. 2009.

LIMA, Luiz Costa. História. Fição. Literatura. São Paulo: Companhia das Letras, 2006.

PESSANHA, José Américo Motta. Bachelard: as asas da imaginação. In: BACHELARD, Gaston. O Direito de Sonhar. Rio de Janeiro: Bertrand Brasil, 1991a, p. $v-\mathrm{xxxi}$.

PIRE, François. De l'imagination poétique dans l'oeuvre de Gaston Bachelard. Paris: José Corti, 1967.

RANCIÈRE, Jacques. Os Nomes da História. São Paulo: EDUC/Pontes, 1994. 
Imaginação e história: um diálogo com Gaston Bachelard

. Políticas da Escrita. Rio de Janeiro: Ed. 34, 1995.

UNICAMP, 2007. - A Memória, a História, o Esquecimento. Campinas: Ed. da . Tempo e Narrativa. Campinas: Papirus, 1994-1997. 3 v.

SARTRE, Jean-Paul. A Imaginação. São Paulo: Abril Cultural, 1978 (Coleção Os Pensadores).

WHITE, Hayden. Meta-História: A imaginação histórica do século XIX. São Paulo: EDUSP, 1995.

. Trópicos do Discurso. São Paulo: EDUSP, 1994. 